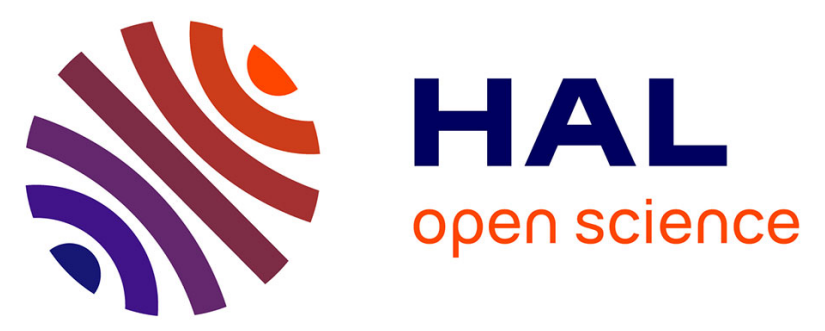

\title{
TactiBelt: Integrating Spatial Cognition and Mobility Theories into the Design of a Novel Orientation and Mobility Assistive Device for the Blind
}

\author{
Marc-Aurèle Rivière, Simon Gay, Edwige Pissaloux
}

\section{To cite this version:}

Marc-Aurèle Rivière, Simon Gay, Edwige Pissaloux. TactiBelt: Integrating Spatial Cognition and Mobility Theories into the Design of a Novel Orientation and Mobility Assistive Device for the Blind. Klaus Miesenberger; Georgios Kouroupetroglou. Computers Helping People with Special Needs, 10897, Springer, pp.110-113, 2018, Lecture Notes in Computer Science, 978-3-319-94273-5. 10.1007/978-3319-94274-2_16. hal-02353413

\section{HAL Id: hal-02353413 \\ https://hal.science/hal-02353413}

Submitted on 7 Nov 2019

HAL is a multi-disciplinary open access archive for the deposit and dissemination of scientific research documents, whether they are published or not. The documents may come from teaching and research institutions in France or abroad, or from public or private research centers.
L'archive ouverte pluridisciplinaire HAL, est destinée au dépôt et à la diffusion de documents scientifiques de niveau recherche, publiés ou non, émanant des établissements d'enseignement et de recherche français ou étrangers, des laboratoires publics ou privés. 


\title{
TactiBelt: integrating spatial cognition and mobility theories into the design of a novel orientation and mobility assistive device for the blind
}

\author{
Marc-Aurèle RIVIERE [0000-0002-5108-3382], Simon GAY [0000-0002-7107-1055] and Edwige \\ PISSALOUX ${ }^{[0000-0001-9891-2531]}$ \\ University of Rouen Normandy, LITIS, France \\ marc.aurele.rivieredetu.univ-rouen.fr
}

\begin{abstract}
The aim of this paper is to introduce a novel functional design for an indoor and outdoor mobility assistive device for the visually impaired, based on the theoretical frameworks of mobility and spatial cognition. The originality of the proposed approach comes from the integration of two main aspects of navigation, locomotion and wayfinding. The cognitive theories which underpin the design of the proposed sensory substitution device, called TactiBelt, are identified and discussed in the framework of spatial knowledge acquisition.

The paper is organized as follows: section 1 gives a brief overview of the sensory substitution framework, while sections $2 \& 3$ introduce the importance of navigation and spatial cognition models for the design of mobility aids. Section 4 details the functional design of the Tactibelt.
\end{abstract}

Keywords: Mobility aid, sensory substitution, spatial cognition, blindness.

\section{Introduction: Some Remarks on Sensory Substitution}

According to the World Health Organization, as of October 2017, 253 million people live with vision impairment worldwide, with 36 million being completely blind.

In the last decades, many devices were developed to compensate for loss of vision, most of them relying on the sensory substitution framework first introduced 50 years ago by Bach-y-Rita [1]. Sensory Substitution, in its most basic definition, consists in conveying information about the environment through "unusual" sensory channels; for example, transmitting information about the distance of remote objects through tactile stimulation. Therefore, Sensory Substitution Devices (SSD) can be seen as a special kind of non-invasive human-machine interface, designed to provide additional (or no longer accessible) information about the environment. SSD devices allow their users to carry out tasks that were previously impossible or troublesome due to a lack of information. SSD are usually comprised of three main elements: sensors, an interface to communicate with the user (usually through touch or sound), and a processing unit to remap the gathered information to the code of the receptive modality.

Sensory substitution mainly relies upon our capacity to actively re-interpret new sensory information and to automate this process through learning, ultimately leading 
to an embodied externalized [2] interaction with the environment, interfaced by the SSD. By allowing them to regain access to parts of their Umwelt, SSDs improve how well Visually Impaired People (VIP) can interact with the world, restoring their sense of autonomy, control, and safety [3]. However, one of the main constraint of SSD design is the amount of information that can be conveyed to the user without creating an excessive cognitive load [4]. Indeed, the amount of information gathered by our vision is much greater than our tactile or auditory "bandwidth" [5], meaning that SSDs must carefully select what information they convey, and how they encode it.

\section{$2 \quad$ Navigation and Blindness}

Autonomous navigation is one of the greatest challenges VIP face, since vision plays a crucial role in gathering the information necessary for many processes involved in this complex task. Recent research supports the idea that VIP can learn the spatial layout of an environment and navigate inside of it as efficiently as the sighted, if given the proper information for this task [6], [7]. Indeed, our spatial representations are amodal [8], meaning they can also be elicited through audition and touch, with functionally equivalent properties. Therefore, with properly designed SSDs, VIP could autonomously perceive, interpret, learn and interact with their spatial environment.

Navigation is traditionally divided into two main categories: wayfinding (also called orientation) and locomotion (or mobility) [9]. Wayfinding refers to the mental processes allowing us to understand the large-scale spatial properties of our environment and localize ourselves amidst it, relatively to salient "visible" or memorized features. Locomotion refers to the mental and physical processes allowing us to move along a chosen path while successfully avoiding obstacles on the way [10].

Many of the current assistive devices for the blind mostly cater to locomotion, but not often to autonomous wayfinding. Indeed, these devices do not provide any largescale information that would allow users to autonomously plan, navigate and update their path, or to find shortcuts. To accomplish this, we need to develop devices that address both locomotion and wayfinding, thus allowing for the emergence of spatial representations. It is with that aim that the TactiBelt system was developed.

\section{The Importance of Spatial Cognition Models in SSD Design}

Gaining a better understanding of the underlying mechanisms of space perception and how these mechanisms adapt to blindness would allow researchers to pinpoint precisely what information is crucial to elicit spatial representations and learning.

According to many spatial cognition theories, to properly compensate for the lack of vision, mobility assistive devices should provide information about important environmental cues, such as landmarks. Landmarks, which can be defined as stable, easily remembered and often visible landscape cues, have been shown to improve the ability of VIP to elaborate and organize mental representations of their environment [11], [12], and to navigate thanks to them. Finally, providing information about the surroundings topography, like the disposition of the roads, might prove helpful by allow- 
ing VIP to better identify their current location, and to foresee incoming direction changes.

\section{The Tactibelt Preliminary Specifications}

Based on the aforementioned recommendations, we put forward the following functional design for the TactiBelt system. The device will interface with the user through a belt fitted with vibrators, worn around the waist. We chose this type of interface because it allows the user to intuitively perceive ego-centered spatial information without requiring any complex information recoding. The belt will have 3 layers of vibrators to allow for a better coding of the elevation of obstacles.

The device will also include 2 front-facing cameras, embedded into a pair of glasses, combined with an inertial unit, to provide stable orientation-aware depth information about nearby obstacles. A GPS chip will provide absolute localization and ego-centered distance information about nearby landmarks. Cartographic data will be collected from online services or from buildings' blueprints for indoor navigation.

The TactiBelt will provide 4 types of information: nearby obstacles, landmarks, the surrounding topography (street intersection nodes), and the current destination. Those 4 types will be distinguishable by their tactile representation, i.e. the specific vibration pattern used for each of them. Periodic pulses of varying frequency and intensity will be used for each type of information, in order to introduce discontinuity in the signal in order to avoid habituation [12]. Additionally, the users will be able to manually add new landmarks (e.g. bus stops, their home, ...).

Those 4 information levels will not be presented simultaneously to avoid a cognitive overload [11], [12]. They will be sent sequentially [11], each being displayed for a varying duration depending on their priority: obstacles will have the highest priority, meaning they will be most frequently displayed and will take precedence over the others if a collision is imminent. The second most important one is the street intersection nodes, followed by the landmarks, and lastly, the destination. A maximum of 7 pieces of information of one type will be transmitted simultaneously, based on the specificities of human working memory [13]. However, this number will be adjustable by the users depending on their preferences and their experience with the device.

The distance and relative position of each element the belt "points to" will be given in an abstract and continuous manner: the vibration's intensity will represent the distance to the element, and the direction of the element will be given by activating the vibrator pointing towards the obstacle's direction. The elevation of an obstacle will be given in a symbolic manner, with a movement either pointing down or up, moving through the 3 layers of vibrators. The landmarks' identity will be given through vocal feedback, with bone conduction headphones to keep the users' audition free.

\section{$5 \quad$ Conclusion and Future Work}

This paper has addressed the concept of a new non-invasive dynamic navigation aid for the blind, the TactiBelt. Its originality arises from the fact that it assists not only 
locomotion through obstacle avoidance, but also spatial integration by providing intuitive information that will allow VIP to mentally map and learn their environment.

This will allow them to navigate autonomously and safely indoors and outdoors, enabling them to participate more actively in society.

Moreover, TactiBelt's adaptive design would make it fit for many uses by sighted people, such as providing dynamic, non-distractive and readily interpretable guidance in visually noisy environments (e.g. a smoky building for firefighters), or as a GPS substitute for drivers, allowing them to keep their eyes on the road at all times.

The system prototyping of the device is currently underway. A thorough evaluation with the targeted end users will be done to assert the relevance of our design, its acceptance by the VIP community and its validation against existing similar devices.

\section{References}

1. P. Bach-y-Rita, C. C. Collins, F. A. Saunders, B. White, et L. Scadden, « Vision substitution by tactile image projection », Nature, vol. 221, n 5184, p. 963-964, mars 1969.

2. M. Auvray, D. Philipona, J. K. O'Regan, et C. Spence, « The perception of space and form recognition in a simulated environment: The case of minimalist sensory-substitution devices », Perception, vol. 36, $\mathrm{n}^{\circ}$ 12, p. 1736-1751, 2007.

3. S. M. Kärcher, S. Fenzlaff, D. Hartmann, S. K. Nagel, et P. König, « Sensory Augmentation for the Blind », Front. Hum. Neurosci., vol. 6, 2012.

4. Á. Kristjánsson et al., « Designing sensory-substitution devices: Principles, pitfalls and potentials », Restor. Neurol. Neurosci., vol. 34, n 5, p. 769-787, sept. 2016.

5. C. Spence, «The skin as a medium for sensory substitution », Multisensory Res., vol. 27, $n^{\circ}$ 5-6, p. 293-312, 2014.

6. D.-R. Chebat, V. Harrar, R. Kupers, S. Maidenbaum, A. Amedi, et M. Ptito, « Sensory Substitution and the Neural Correlates of Navigation in Blindness », in Mobility of Visually Impaired People, E. Pissaloux et R. Velazquez, Éd. Cham: Springer International Publishing, 2018, p. 167-200.

7. E. E. Pissaloux, R. Velazquez, et F. Maingreaud, «A New Framework for Cognitive Mobility of Visually Impaired Users in Using Tactile Device », IEEE Trans. Hum.-Mach. Syst., vol. 47, nº 6, p. 1040-1051, déc. 2017.

8. J. M. Loomis, R. L. Klatzky, et N. A. Giudice, « Representing 3D space in working memory: Spatial images from vision, hearing, touch, and language », in Multisensory imagery, Springer, 2013, p. 131-155.

9. D. R. Montello, « Navigation », in The Cambridge Handbook of Visuospatial Thinking, P. Shah et A. Miyake, Éd. Cambridge: Cambridge University Press, 2005, p. 257-294.

10. D. Waller et L. Nadel, Éd., Handbook of spatial cognition. Washington: American Psychological Association, 2013.

11. S. Meers et K. Ward, «A substitute vision system for providing 3D perception and GPS navigation via electro-tactile stimulation », 2005.

12. M. Srikulwong et E. O’Neill, «A comparative study of tactile representation techniques for landmarks on a wearable device », 2011, p. 2029.

13. G. A. Miller, « The magical number seven, plus or minus two: some limits on our capacity for processing information. », Psychol. Rev., vol. 63, nº 2, p. 81-97, 1956. 